\title{
The Intermediary Role of English Teachers in Organizing Cooperative Learning
}

\author{
Gan He* \\ School of Foreign Languages \\ Hunan University of Technology \\ Zhuzhou City, China
}

\author{
Xiaoli Huang \\ Department of Physical Culture \\ University of South China \\ Hengyang City, China
}

\begin{abstract}
Group cooperative learning breaks the traditional form of seating and brings unprecedented challenges to the organization of teaching. Teaching results are not as good as expected especially in terms of class organization. The paper aims to tackle the problem from the two parties involved in teaching: teachers and students. It finds out that only when students become the active learner or in another word, when the class is student-centered that cooperative learning will start, and only when the teachers' guiding becomes proper that the class can become student-centered. When both teachers and students are cooperative in class the above-mentioned result will be achieved.
\end{abstract}

Keywords-teacher-mediator; student-centered; initiative; cooperative learning

\section{INTRODUCTION}

Group cooperative learning breaks the traditional form of seating and brings unprecedented challenges to the organization of teaching. What usually happens is that: after teachers assign a certain teaching task and ask students to have a group discussion, members of some group explained away one's duty for whom to speak on behalf of the team by finding all kinds of excuses, some members are active, some simply served as the audience, some others even chat in Chinese about something that has nothing to do with the English teaching. The classroom looks very lively and the atmosphere is very active, but the teaching effect is not ideal. That is what called "active does not indicate effectively [7]". The reasons for such teaching results mainly include:

\section{A. Students Are not Well Prepared}

For example, when the task is discussing people's appearance, teachers usually assign students to collect some pictures of their favorite stars and then describe them in English. If students don't get prepared in advance, then there is nothing they can do in class.

\section{B. Individual Students Are Different}

Individual students are different in personality, learning habits, listening habits, basic skills, etc[3]. Some are extroverted, some don't like to speak, and some have not stored enough knowledge.

\section{Teachers' Instructions Are Not Clear}

Teachers' instructions on the tasks are not clear or tasks are not suitable for students to complete, resulting in students not knowing how to start [2]. Then it is difficult for teachers to organize teaching.

\section{Teachers’ Wrong Attitudes}

Teachers have not paid enough attention to the poor students or they are afraid that asking them questions will affect the classroom effect and delay teaching schedule. Therefore, the underachievers will become indifferent and behave as if they are audiences, or they disrupt the teaching order instead [1].

\section{Making Students the Main Body OF StUdy}

Educator Tao Xingzhi once said, "It is not teachers' duty to teach, but enable students to learn. The way one teaches must be the way one learns [8]." Due to insufficient trust in the ability of students, and the underestimation of students' potential, in traditional lectures, teachers repeat the important and difficult points. They talk much while students don't say anything, let alone self-study. Some students' self-learning ability has been buried under the long-term "spoon-feeding" teaching method.

How can we give full play to students' initiative so that each student can actively participate in the classroom learning, turning "Someone wants me to learn" to "I want to learn"? To fulfill this, the practice of student-centered classroom teaching is required. Teachers play the role of designing and organizing all kinds of classroom activities for students, and preparing for possible problems that might emerge. After leading-in, the teacher should give a full or complete place for students. He or she can listen attentively and record the problems or errors as a spectator, and then make a concise summary to explain and comment on the information acceptance, transmission and language application of the students inactivity. While the students became the main role in the class, they are encouraged to be active in communication.

My experience says: It is better to teach someone to fish than to give him fish. Teaching students how to learn is the real solution to making them masters of the classroom. Teachers should make students shift from "someone wants me to learn" to "I want to learn" to "I will learn" and "it is easy to learn". 


\section{A. Teaching Students to "Read" Books}

Based on the characteristics of foreign language and the development trend of examinations for English majors in recent years, I think students should first learn to "read" books. Only by truly understanding and reading through textbooks can students deepen their understanding of the knowledge and turn passive listening into their own reading experience.

\section{B. Teaching Students to Ask Questions}

As the guide of teaching activities, teachers' duty is to inspire students, guide and lead them to the truth step by step. In this process, students need to ask questions constantly and think actively. Many students don't know how to face the questions and topics in the exam, which indicates that they lack of practice in this aspect. The material in the book or the current events in the newspapers can be used as the base for students to ask questions. Students' ability to ask questions and learn independently can be well cultivated by "asking questions, analyzing problems and solving problems".

\section{Teaching Students to Answer Questions}

In English language examinations, there are various types of test topics, including multiple-choice, analyzing, reading comprehension, among others. Some topics are examined in the form of the written paper, some in the form of listening or watching video. The common problems in examination in recent years include too little vocabulary and not being able to make an effective judgment on the information.

\section{Teaching Students to Be Good Listeners}

When teachers encourage students to speak, they should, at the same time, praise and make comments on students' activities, guiding students to respect for others' views and tolerant different others, learn from each other, learn to collect data, and learn to express their views. Teachers should help those who have difficulty in expressing by providing necessary language resources, such as sentence patterns, vocabulary, fixed collocation, etc.

\section{E. Teaching Students to Preview before Class}

In the first class, it should be clearly indicated which tasks should be completed by students themselves, which need the help of teachers, and which should be completed by teachers and students together. The task deixis should be clear, so that students can understand the goal of the task, the process and requirements of completing the task.

\section{TEACHERS AS MEDIATOR}

As communicators of human culture, teachers play a role of bridge and link in the inheritance and development of human culture. "Teacher's duty is, therefore, preaching, imparting knowledge, and solving doubts[5]", this is the accurate summary of the role of teachers in ancient China. With the development of human civilization and social requirements, the role of teachers has been endowed with more contents and meanings, making teachers assume greater responsibility and play a more important role and influence in human social life.
Most of the teachers in the classroom belong to the following two kinds: one is, the teacher gives lectures full of passion and with the vivid explanation. Students' actively participate with great interest in learning. Both teaching and learning immersed in a relaxed and happy atmosphere. Students learn lightheartedly, experiencing the happiness and joy of teaching and learning. Such teaching has a good effect and usually making outstanding achievements. The other is, the teacher's explanation is dull and tedious. Student doing exercises mechanically and repeatedly. The teaching method is rigid, the teaching atmosphere dull, student indifference, and no communication. The classroom is like a pool of stagnant water. The teaching has a poor effect. Why? By the same textbook, same teaching hour, the teaching effect is completely different? In fact, this is due to the different classroom atmosphere.

How can a teacher liven up the class? This requires teachers to play an intermediary role in the class. Requirements are as follows:

\section{A. Variety of Leading-in Methods Should Be Adopted}

The leading-in of new lectures is an important part of teaching -- "a good beginning is half the success[6]." In the initial stage of teaching, we should quickly attract students' attention and bring their thoughts into a specific learning situation, which plays a crucial role in the success of a class. The leading-in should be interesting, targeted, and with novel materials. The leading-in methods can be varied depending on whom, when and where, not sticking to one pattern. 1) Leading-in with objects. We can show a real, vivid object in front of the students, stimulate their interest in learning and actively participate in class with enthusiasm. It should let the students get excited so that they can immediately involve in. 2) Problem introduction. We can raise some questions that students are interested in and attract them participating in discussion, naturally integrating into the class, and actively explore the answers to questions.

\section{B. Creating a Pleasant Classroom Environment}

According to modern education theory, school education is not only about knowledge exchange, but also about emotion exchange[9]. Teaching activities are completed under the mutual interaction and restriction of knowledge and emotion. It is impossible to achieve an ideal teaching effect if only paying attention to the explanation of knowledge but neglecting the communication of emotion. To create a pleasant classroom environment, we should pay attention to the following points:

1) Bring your smile into the classroom. "Smile is the professional needs of teachers[4]". No matter what unpleasant things teachers encounter in life, they cannot infect students with this kind of emotion. Teachers should have a high degree of control.

2) Teachers should be good at arousing students' thirst for knowledge, making students eager for knowledge and guiding students to actively explore new knowledge, which is the best environment for teachers to create for classroom teaching. 
3) education should be oriented to all students. Teaching students in accordance with their aptitude, teachers should give every student the opportunity to succeed, should not discriminate against poor students, while motivation, encouragement is the essence of good teaching. Teachers should make every student learn in the "psychological security" atmosphere, and develop comprehensively.

\section{Teachers Should Exert Their Personal Charm in Teaching Process}

In the teaching process, teachers should use rich facial expressions to infect students, use various gestures, and another body language to motivate students, relax students' tension with a smile, and make students confident and interested in the lecture with humorous words and expectant expressions. The teacher is a performer, whose attitude, words, deeds, every twinkle and smile can greatly affect the audience - students. If teachers put heart and soul into teaching and are energetic in teaching, students will naturally follow them and concentrate on the class. At the same time, teachers should use all kinds of encouraging words. Teachers' sincere praise to students will give great encouragement to students and help create a positive and harmonious classroom atmosphere. "Congratulations." you are right!”, "that’s it!", "well done!", "Try, you could do it." These words can make students more confident and actively participate in classroom teaching.

\section{Encouraging Active Classroom Participation}

James, an American psychologist, once said that the deepest quality of human nature is the desire to be appreciated. In class, the teacher should pay attention to the growth of each student, and give a different evaluation to all answers of the students. Praising and encouraging their progress, and protecting their enthusiasm to speak. When correcting students' mistakes, teachers should pay attention to their manners, no irony, and sarcasm to contuse students' enthusiasm. Besides, teachers must treat students equally, not preferring excellent students while ignoring the medium. Teachers can sign some task suitable for them, let them enjoy the success of learning and growing with the others, otherwise, the teacher may lose color in the eyes of those students. And students may lose enthusiasm in answering questions or even learning. Teachers' "teaching" should serve students' "learning". Teachers should study students and understand their psychology and needs in learning. The Teaching should be organized according to the principle of English teaching, creating a pleasant environment for learning, providing them with all kinds of opportunities to use English, enable them fully contact English and use English, maximize space for students to display talent, and play with English, so that students would always keep active in the process of learning English, making the teaching a process of developing and improving students' listening, speaking, reading and writing ability.

\section{E. Using Effective Evaluation Means}

Evaluation plays an important role in English teaching. Through evaluation, teachers can transfer their understanding and emotion to students' behaviors consciously or unconsciously. If students get positive feedback in learning, they feel their intrinsic value get acknowledged by the outside world, they would gain a sense of achievement, which would enhance their self-esteem and self-confidence, and having a joy of self-fulfilling, followed by the enthusiasm of learning a foreign language and gradually raise the levels of needs of learning. And vice versa. Teachers should be good at using effective evaluation methods to capture students' excellence, using more praise, less criticism, more affirmation, less negation, so that every student can learn in a relaxed and happy manner and be enthusiastic in the study and have a master of the basic knowledge of English.

\section{CONCLUSION}

All in all, as English teachers, we should realize that our education target is a living person, not just a container to receive the knowledge taught by teachers. Students have the desire to express themselves and get recognition from others. In the teaching activities, if students can really become the main body in the teaching, if students learned how to learn, learned how to communicate, understood that "we all have something to learn from others.", mastered the learning method, and became the master of learning, then they can keep on growing from cooperative learning, and calmly face the test. This is also the original intention of implementing education reform: reducing students' burden and advocating quality education.

\section{REFERENCES}

[1] Perry, Justin C., Xiongyi Liu, and Yvona Pabian. "School engagement as a mediator of academic performance among urban youth: The role of career preparation, parental career support, and teacher support." The Counseling Psychologist 38.2, 2010, pp.269-295.

[2] Urhahne, Detlef. "Teacher behavior as a mediator of the relationship between teacher judgment and students' motivation and emotion." Teaching and Teacher Education 45, 2015, pp.73-82.

[3] Virtanen, Tuomo E., et al. "Student behavioral engagement as a mediator between teacher, family, and peer support and school truancy." Learning and Individual Differences 36, 2014, pp.201-206.

[4] Clouet, Richard. "Between one's own culture and the target culture: The language teacher as intercultural mediator." Porta Linguarum: Revista internacional de didáctica de las lenguas extranjeras 5, 2006, pp.53-62.

[5] Olsen, Brad, and Lisa Kirtman. "Teacher as Mediator of School Reform: An Examination of Teacher Practice in 36 California Restructuring Schools." Teachers College Record 104.2, 2002, pp.301-24.

[6] Grayson, Jessica L., and Heather K. Alvarez. "School climate factors relating to teacher burnout: A mediator model." Teaching and teacher education 24.5, 2008, pp.1349-1363.

[7] Wright, Gloria Brown. "Student-centered learning in higher education." International Journal of Teaching and Learning in Higher Education 23.1, 2011, pp.92-97.

[8] Wang, Dan. "The dilemma of time: Student-centered teaching in the rural classroom in China." Teaching and Teacher Education 27.1, 2011, pp.157-164.

[9] Rogers, Carl R., Harold C. Lyon, and Reinhard Tausch. On becoming an effective teacher: Person-centered teaching, psychology, philosophy, and dialogues with Carl R. Rogers and Harold Lyon. Routledge, 2013. 